\title{
Pengajar Kredibel dan Mahasiswa Jujur: Literasi Ekonomi Tinggi?
}

\author{
Albrian Fiky Prakoso*1, Riza Yonisa Kurniawan², Muhammad Abdul Ghofur ${ }^{3}$ \\ Program Studi Pendidikan Ekonomi \\ Universitas Negeri Surabaya \\ Surabaya, Indonesia
}
e-mail: albrianprakoso@unesa.ac.id ${ }^{* 1}$,rizakurniawan@unesa.ac.id², muhammadghofur@unesa.ac.id ${ }^{3}$

\section{Riwayat Artikel Tanggal diajukan: 18 Februari 2020 \\ Tanggal diterima : 2 Juni 2020 \\ Tanggal dipublikasikan: 29 Juni 2020}

Pengutipan: Prakoso, A. F Kurniawan, R.Y. \& Ghofur, M.A (2020). Pengajar Kredibel dan Mahasiswa Jujur: Literasi Ekonomi Tinggi?. Jurnal

Pendidikan

Ekonomi

Undiksha, 12 (1), 60-67

\begin{abstract}
Abstrak
Tidak sedikit mahasiswa memandang bahwa melakukan kecurangan saat ujian adalah cara yang paling efektif untuk meningkatkan nilai akademik. Banyak dari mereka yang melakukan itu karena menganggap dosen yang mengajar kurang kredibel. Penelitian ini bertujuan untuk mengetahui apakah kredibilitas dosen dan ketidakjujuran mahasiswa dapat mempengaruhi tingkat literasi ekonomi mahasiswa. Data penelitian ini diambil dari adalah 77 mahasiswa yang dianalisis menggunakan pendekatan kuantitatif. Hasil penelitian menunjukkan bahwa semakin tinggi kredibilitas dosen maka akan semakin rendah kecurangan akademik. Semakin kredibel dosen maka semakin tinggi literasi ekonomi mahasiswa. Akan tetapi ternyata kecurangan akademik mahasiswa tidak menentukan tingkat literasi ekonomi mahasiswa. Hal menarik dari hasil penelitian ini adalah kemampuan dosen dalam menjawab pertanyaan ternyata sangat menentukan persepsi mahasiswa tentang kredibilitas dosennya, namun ketika dosen semakin dianggap kredibel justru membuat mahasiswa untuk melakukan kecurangan.
\end{abstract}

Kata kunci: kredibilitas dosen; kecurangan akademik; literasi ekonomi

\begin{abstract}
Many students see that cheating during an exam is the most effective way to improve academic grades. Many of them do that because they think teaching the lecturer is less credible. This study aims to determine whether the credibility of lecturers and student dishonesty can affect the level of economic literacy of students. The number of respondents in this study amounted to 77 students and analyzed using a quantitative approach. The results showed that the higher the credibility of lecturers, the lower the academic cheating. The more credible the lecturer, the higher the economic literacy of students. However, it turns out that student academic cheating does not determine the level of economic literacy of students. The exciting thing from the results of this study is that the ability of lecturers to answer questions turns out to determine students' perceptions about the credibility of their lecturers. Still, when students call lecturers more credible, it makes students commit fraud.
\end{abstract}

Keywords: lecturer credibility; academic cheating; economic literacy 


\section{PENDAHULUAN}

Berbagai upaya telah dilakukan
banyak Lembaga Pendidikan untuk
meningkatkan hasil belajar peserta didiknya. Meningkatkan kredibilitas dosen misalnya melalui berbagai pelatihan di berbagai bidang keahlian. Banyak peneliti menganalisis tentang kredibilitas pengajar dalam suatu Lembaga Pendidikan (de Guzman et al., 2007; Edwards, Edwards, Spence, Harris, \& Gambino, 2016; Ghofur, 2013). Akan tetapi kredibilitas pengajar di tingkat pendidikan masih sangat jarang, khususnya di prodi Pendidikan ekonomi Universitas Negeri Surabaya (Unesa) belum pernah dilakukan, terutama untuk mengetahui seberapa besar pengaruhnya terhadap literasi ekonomi mahasiswa.

Kecenderungan umum yang dialami mahasiswa di Indonesia adalah mereka tidak percaya diri pada kemampuannya. Ketidakpercayaan diri tersebut mendorong mereka untuk melakukan kecurangan akademik. Hal ini juga sering diteliti oleh banyak peneliti misalnya: Lambert, Hogan, and Barton (2003); Austin et al. (2006); Donse and Groep, (2013); dan Hakim et al., (2018).

Sampai saat ini, memang sudah banyak yang meneliti literasi ekonomi mahasiswa di Unesa (Aningsih \& Soejoto, 2018; Murniatiningsih, 2017; Rafsanjani, Sholikhah, \& Prakoso, 2019; Sahroh, 2018; Zulatsari \& Soesatyo, 2018). Akan tetapi penelitian tersebut lebih banyak berhubungan dengan ilmu manajemen dan kurikulum. Penelitian tentang literasi ekonomi yang berhubungan dengan kredibilitas dosen dan kecurangan akademik mahasiswa belum pernah dilakukan. Banyak dosen yang beranggapan jika kredibilitas dosen tinggi maka mahasiswa akan memiliki literasi ekonomi yang tinggi dan tidak perlu melakukan kecurangan akademik.

Walaupun upaya Unesa untuk meningkatkan kredibilitas dosennya sudah sangat baik, akan tetapi permasalahan masih saja terjadi. Mahasiswa tetap melakukan kecurangan akademik dan mata kuliah teori ekonomi masih menjadi hal yang sulit bagi mereka.

Hipotesis penelitian ini adalah semakin baik kredibilitas dosen maka mahasiswa akan cenderung tidak melakukan kecurangan akademik dan memiliki literasi ekonomi yang tinggi. Melalui penelitian ini akan didapatkan informasi, indikator kredibilitas dosen mana yang perlu ditingkatkan dan kecurangan akademik mahasiswa mana yang harus segera diperbaiki Unesa.

\section{METODE}

Penelitian ini dilakukan dengan pendekatan kuantitatif. Alat analisis yang dipilih yaitu Structural Equation Modeling (SEM) dengan metode penghitungan koefisien partial least square (PLS). Alat ini dipilih karena dianggap sesuai dengan kebutuhan analisis yaitu menguji pengaruh antar variabel laten dan menganalisis setiap indikator dari masing-masing variabel tersebut. Metode PLS juga tidak menuntut jumlah data yang besar sehingga populasi mahasiswa prodi Pendidikan ekonomi angkatan 2017 yang berjumlah 77 orang sudah bisa dianggap cukup.

Aplikasi yang digunakan dalam analisis ini adalah WarpPls. Menurut Solimun, Fernandes and Nurjannah (2017) jumlah sampel pada SEM Warppls bisa didapatkan melalui rule of thumb. Salah satunya adalah sepuluh kali banyaknya variabel (mengingat Warppls merupakan bagian dari analisis multivariat). Jumlah variabel dalam penelitian ini adalah 3 maka sepuluh kalinya adalah 30 . Selain itu SEM Warppls juga sudah melakukan resampling. Jadi dengan jumlah sampel yang sedikit, informasi yang didapat akurat dan data bisa berdistribusi normal. Dengan demikian jumlah sampel penelitian ini adalah 77 sudah dapat dilakukan analisis.

Indikator kredibilitas Dosen antara lain adalah: Keahlian, Pengalaman, Pemikiran, Meyakinkan (Ghofur, 2013). Sedangkan indikator kecurangan akademik antara lain Menyiapkan catatan kecil saat ujian, Menggunakan catatan/ contekan saat ujian, Menyalin jawaban orang lain saat ujian, Menggunakan metode yang tidak jujur agar tahu materi yang diujikan, Menyalin jawaban orang lain tanpa sepengetahuannya, Membantu orang lain untuk curang saat ujian, Menjiplak karya orang lain, Memalsukan sumber rujukan, Melakukan kerjasama dengan dosen terkait 
nilai individu, Melakukan plagiasi dalam mengerjakan tugas yang diadopsi dan dimodifikasi sesuai dengan sensitivias lingkungan akademik (Sagoro, 2013). Sedangkan indikator literasi ekonomi diperoleh dari skor tes literasi ekonomi yang telah diadopsi dan dimodifikasi sesuai dengan materi teori ekonomi yang pernah diterima oleh mahasiswa program studi Pendidikan ekonomi angkatan 2017 (Walstad, Rebeck, \& Butters, 2013).

\section{HASIL DAN PEMBAHASAN}

Model Fit

Hasil uji Goodness of fit digunakan untuk melihat indeks dan ukuran kebaikan hubungan antar variabel laten dari model yang dibangun. Hasil dari uji menggunakan Warppls diringkas dalam tabel 1.

Hasil uji goodness of fit menunjukkan bahwa model hubungan antar variabel yang dibangun dalam penelitian ini beberapa telah memenuhi model fit. Menurut (Solimun et al., 2017) persyaratan model memenuhi kriteria fit atau tidak tergantung pada tujuan penelitian kita. Jika tujuan penelitian adalah mencari model yang terbaik maka semua kriteria fit harus terpenuhi. Sedangkan tujuan penelitian ini lebih pada melihat dan menganalisis pengaruh antara variabel eksogen terhadap endogennya, tidak mencari model terbaik sehingga apabila terdapat satu atau dua kriteria fit yang terpenuhi maka penelitian bisa dilanjutkan.

Tabel 1. Goodness of fit Model Penelitian

\begin{tabular}{|c|c|c|c|c|}
\hline No. & $\begin{array}{l}\text { Model fit and quality } \\
\text { indices }\end{array}$ & Kriteria Fit & $\begin{array}{c}\text { Hasil } \\
\text { Analisis }\end{array}$ & Keterangan \\
\hline 1 & $\begin{array}{l}\text { Average path } \\
\text { coefficient (APC) }\end{array}$ & $\mathrm{P}<0,05$ & $\begin{array}{l}0,390 \\
(P<0,001)\end{array}$ & $\begin{array}{l}\text { Memenuhi syarat } \\
\text { model Fit }\end{array}$ \\
\hline 2 & $\begin{array}{l}\text { Average R-squared } \\
\text { (ARS) }\end{array}$ & $P<0,05$ & $\begin{array}{l}0,348 \\
(P=0,002)\end{array}$ & $\begin{array}{l}\text { Memenuhi syarat } \\
\text { model Fit }\end{array}$ \\
\hline 3 & $\begin{array}{l}\text { Average adjusted } R \text { - } \\
\text { squared (AARS) }\end{array}$ & $P<0,05$ & $\begin{array}{l}0,346 \\
(P=0,004)\end{array}$ & $\begin{array}{l}\text { Memenuhi syarat } \\
\text { model Fit }\end{array}$ \\
\hline 4 & $\begin{array}{l}\text { Average block VIF } \\
\text { (AVIF) }\end{array}$ & $\begin{array}{l}\text { acceptable if }<=5, \\
\text { ideally }<=3.3\end{array}$ & 1,293 & Ideal \\
\hline 5 & $\begin{array}{l}\text { Average full collinearity } \\
\text { VIF (AFVIF) }\end{array}$ & $\begin{array}{l}\text { acceptable if }<=5, \\
\text { ideally }<=3.3\end{array}$ & 1,264 & Ideal \\
\hline 6 & Tenenhaus GoF (GoF) & $\begin{array}{l}\text { small }>=0.1, \\
\text { medium }>=0.25, \\
\text { large }>=0.36\end{array}$ & 0,389 & Large \\
\hline 7 & $\begin{array}{l}\text { Sympson's paradox } \\
\text { ratio (SPR) }\end{array}$ & $\begin{array}{l}\text { acceptable if }>= \\
0.7, \text { ideally }=1\end{array}$ & 1,000 & Ideal \\
\hline 8 & $\begin{array}{l}R \text {-squared contribution } \\
\text { ratio (RSCR) }\end{array}$ & $\begin{array}{l}\text { acceptable if }>= \\
0.9, \text { ideally }=1\end{array}$ & 1,000 & Ideal \\
\hline 9 & $\begin{array}{l}\text { Statistical suppression } \\
\text { ratio (SSR) }\end{array}$ & acceptable if $>=0.7$ & 1,000 & Diterima \\
\hline 10 & $\begin{array}{l}\text { Nonlinear bivariate } \\
\text { causality direction ratio } \\
\text { (NLBCDR) }\end{array}$ & acceptable if $>=0.7$ & 1,000 & Diterima \\
\hline
\end{tabular}

Analisis Indikator dan Loading Factor

Hasil uji untuk masing-masing indikator yang digunakan dalam setiap variabel di penelitian ini menunjukkan faktor muatan (loading factor) sebagai mana ditunjukkan pada tabel 2. Pada tabel ini juga disajikan kondisi empiris pada tiap- tiap indikator. Kondisi empiris ini sangat bermanfaat sebagai dasar pengambilan kebijakan demi peningkatan kualitas pembelajaran mahasiswa.

Ketika muatan faktor (loading factor) semakin besar, maka mengindikasikan bahwa indikator semakin kuat 
mencerminkan atau menjadi indikator penting dalam variabel tersebut. Dari beberapa variabel, indikator yang penting adalah:

a. Variabel Kredibilitas Dosen (X1) dengan indikator penting adalah Pemikiran (X1.3) dengan muatan faktor yaitu 0,918 dengan kondisi empiris yang cukup sehingga perlu segera ditingkatkan atau segera diperbaiki.

b. Variabel Kecurangan Akademik (Y1) dengan indikator penting adalah menyalin jawaban orang lain tanpa sepengetahuannya (Y1.5) dengan muatan faktor yaitu 0,813 dengan kondisi tinggi (Skor 4) sehingga hal ini perlu mendapat perhatian khusus untuk dianalisis lebih lanjut.

Tabel 2. Analisis Indikator dan Loading Factor

\begin{tabular}{|c|c|c|c|c|}
\hline No & Indikator & $\begin{array}{l}\text { Muatan } \\
\text { faktor }(0-1)\end{array}$ & $\begin{array}{l}\text { Skor Kondisi } \\
\text { Empiris (1-5) }\end{array}$ & Saran \\
\hline 1 & Keahlian (X1.1) & 0,852 & 4,1 & Dipertahankan \\
\hline 2 & Pengalaman (X1.2) & 0,873 & 3,7 & Ditingkatkan \\
\hline 3 & Pemikiran (X1.3) & 0,918 & 3,9 & Segera Ditingkatkan \\
\hline 4 & Meyakinkan (X1.4) & 0,844 & 4,1 & Dipertahankan \\
\hline 5 & $\begin{array}{l}\text { Menyiapkan catatan kecil } \\
\text { saat ujian (Y1.1) }\end{array}$ & 0,500 & 3,8 & Diperbaiki \\
\hline 6 & $\begin{array}{l}\text { Menggunakan catatan/ } \\
\text { contekan saat ujian (Y1.2) }\end{array}$ & 0,474 & 4,1 & Diperbaiki \\
\hline 7 & $\begin{array}{l}\text { Menyalin jawaban orang } \\
\text { lain saat ujian (Y1.3) }\end{array}$ & 0,697 & 3,6 & Diperbaiki \\
\hline 8 & $\begin{array}{l}\text { Menggunakan metode yang } \\
\text { tidak jujur agar tahu materi } \\
\text { yang diujikan (Y1.4) }\end{array}$ & 0,749 & 4 & Diperbaiki \\
\hline 9 & $\begin{array}{l}\text { Menyalin jawaban orang } \\
\text { lain tanpa } \\
\text { sepengetahuannya (Y1.5) }\end{array}$ & 0,813 & 4 & Segera Diperbaiki \\
\hline 10 & $\begin{array}{l}\text { Membantu orang lain untuk } \\
\text { curang saat ujian (Y1.6) }\end{array}$ & 0,728 & 4,5 & Segera Diperbaiki \\
\hline 11 & $\begin{array}{l}\text { Menjiplak karya orang lain } \\
(\mathrm{Y} 1.7)\end{array}$ & 0,670 & 4,8 & Segera Diperbaiki \\
\hline 12 & $\begin{array}{l}\text { Memalsukan sumber } \\
\text { rujukan (Y1.8) }\end{array}$ & 0,430 & 4,7 & Diperbaiki \\
\hline 13 & $\begin{array}{l}\text { Melakukan kerjasama } \\
\text { dengan dosen terkait nilai } \\
\text { individu (Y1.9) }\end{array}$ & 0,245 & 4,9 & Diperbaiki \\
\hline 14 & $\begin{array}{l}\text { Melakukan plagiasi dalam } \\
\text { mengerjakan tugas (Y1.10) }\end{array}$ & 0,610 & 4,2 & Segera Diperbaiki \\
\hline
\end{tabular}

Hasil Pengujian Hipotesis

Terdapat dua jenis pengujian hipotesis dalam penelitian ini yaitu pengaruh langsung dan tak langsung. Pertama akan ditampilkan pengaruh langsung terlebih dahulu yang merupakan $H 1$, H2, dan $H 3$. Disusul kemudian pengaruh tak langsung yaitu $\mathrm{H} 4$.

Hipotesis pertama $(\mathrm{H} 1)$ menyatakan: Ada Pengaruh Kredibilitas Dosen (X1) terhadap Kecurangan Akademik (Y1). Hasil pengolahan data menunjukkan pengaruh Kredibilitas (X1) terhadap Kecurangan Akademik Mahasiswa (Y1) dengan koefisien jalur sebesar 0,403 dengan nila $p$ lebih kecil 0,001 . Mengingat p lebih kecil dari 0,01 maka dikatakan highly siginificant, sehingga hipotesis tersebut diterima. Koefisien jalur bertanda positif $(0,403)$ mengindikasikan bahwa ketika Dosen dianggap oleh mahasiswa semakin Kredibel (X1) maka Kecurangan Akademik Mahasiswa (Y1) makin meningkat. 


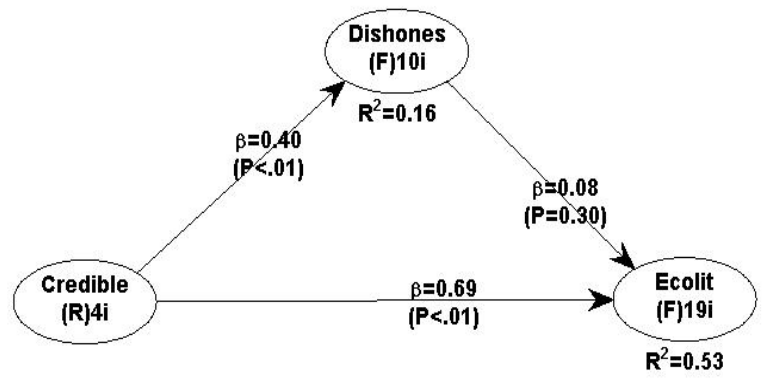

Gambar 1. Hasil Uji Hipotesis

Hipotesis kedua $(\mathrm{H} 2)$ yaitu bahwa

Ada Pengaruh Kredibilitas Dosen (X1) terhadap Literasi Ekonomi Mahasiswa (Y2). Pengaruh Kredibilitas Dosen (X1) terhadap Literasi Ekonomi Mahasiswa (Y2) ini mempunyai nilai koefisien jalur sebesar 0,691 dan $p<0,001$. Mengingat $p$ lebih kecil dari 0,01 maka juga bisa disimpulkan mempunyai pengaruh yang highly siginificant, sehingga hipotesis kedua juga diterima diterima. Koefisien jalur bertanda positif (0,691) mengindikasikan bahwa semakin baik Kredibelitas Dosen (X1) maka Literasi Ekonomi Mahasiswa (Y2) juga makin meningkat.

Table 3. Hubungan antar variabel

\begin{tabular}{llccl}
\hline \multicolumn{2}{c}{ Hubungan antar Variabel (Variabel Penjelas } \\
$\rightarrow$ variabel Respon) & $\begin{array}{c}\text { Koefisien } \\
\text { jalur }\end{array}$ & p-value & Keterangan \\
\hline Kredibilitas Dosen (X1) & $\begin{array}{l}\text { Kecurangan Akademik } \\
\text { Mahasiswa (Y1) }\end{array}$ & 0,403 & $<0,001$ & $\begin{array}{l}\text { Highly } \\
\text { Kredibilitas (X1) }\end{array}$ \\
$\begin{array}{l}\text { Literasi Ekonomi } \\
\text { Mahasiswa (Y2) }\end{array}$ & 0,691 & $<0,001$ & $\begin{array}{l}\text { Highly } \\
\text { Significant }\end{array}$ \\
$\begin{array}{l}\text { Kecurangan Akademik } \\
\text { (Y1) }\end{array}$ & $\begin{array}{l}\text { Literasi Ekonomi } \\
\text { Mahasiswa (Y2) }\end{array}$ & 0,075 & 0,301 & $\begin{array}{l}\text { Not } \\
\text { Significant }\end{array}$ \\
\hline
\end{tabular}

Hipotesis kedua $(\mathrm{H} 2)$ yaitu bahwa Ada Pengaruh Kredibilitas Dosen (X1) terhadap Literasi Ekonomi Mahasiswa (Y2). Pengaruh Kredibilitas Dosen (X1) terhadap Literasi Ekonomi Mahasiswa (Y2) ini mempunyai nilai koefisien jalur sebesar 0,691 dan $p<0,001$. Mengingat $p$ lebih kecil dari 0,01 maka juga bisa disimpulkan mempunyai pengaruh yang highly siginificant, sehingga hipotesis kedua juga diterima diterima. Koefisien jalur bertanda positif $(0,691)$ mengindikasikan bahwa semakin baik Kredibelitas Dosen (X1) maka Literasi Ekonomi Mahasiswa (Y2) juga makin meningkat.

Hipotesis ketiga $(\mathrm{H} 3)$ dimana menyatakan Ada Pengaruh Kecurangan
Akademik Mahasiswa (Y1) terhadap Literasi Ekonomi Mahasiswa (Y2). Ketika mahasiswa melakukan banyak kecurangan maka diindikasikan akan menjadi salah satu pemicu rendahnya literasi ekonomi. Hasil analisis data menunjukkan pengaruh Kecurangan Akademik Mahasiswa (Y1) terhadap Literasi Ekonomi Mahasiswa (Y2) menunjukkan nilai koefisien jalur sebesar 0,075 dengan nilai $p$ sebesar 0,301. Karena nilai $p$ lebih besar dari 0,01 maka dikatakan not siginificant, sehingga hipotesis tersebut ditolak. Jadi tingkat kecurangan akademik yang dilakukan mahasiswa tidak mempunyai pengaruh signifikan terhadap tingkat literasi ekonomi mereka.

Tabel 4. Pengaruh Tak Langsung antar variabel

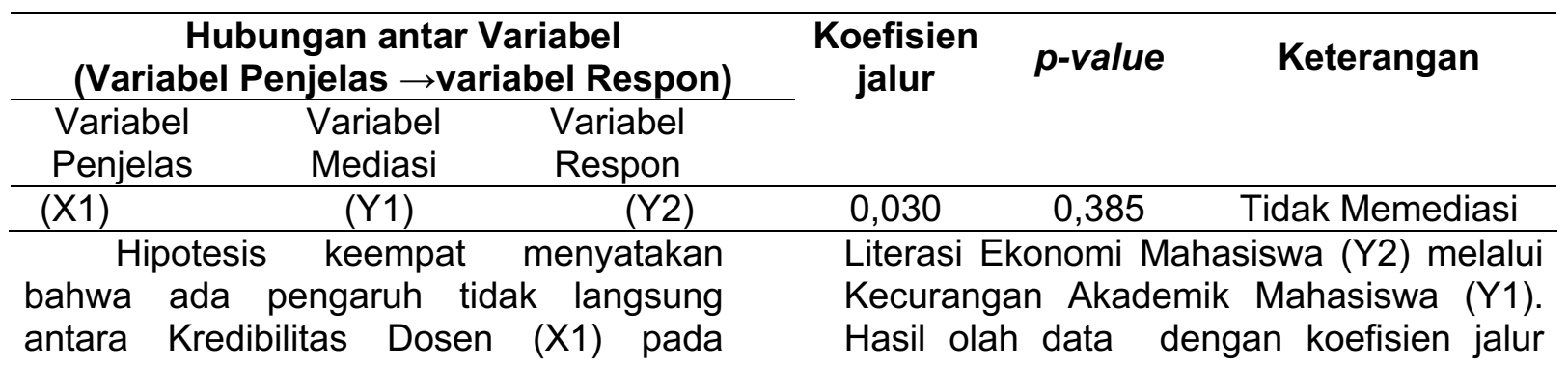


sebesar 0,030 dan $p=0,385$. Mengingat $p$ lebih besar dari 0,1 maka dikatakan not significant atau bukan merupakan mediasi, sehingga hipotesis tersebut ditolak.

Hipotesis keempat menyatakan bahwa ada pengaruh tidak langsung antara Kredibilitas Dosen (X1) pada Literasi Ekonomi Mahasiswa (Y2) melalui Kecurangan Akademik Mahasiswa (Y1). Hasil olah data dengan koefisien jalur sebesar 0,030 dan $p=0,385$. Mengingat $p$ lebih besar dari 0,1 maka dikatakan not significant atau bukan merupakan mediasi, sehingga hipotesis tersebut ditolak.

Kredibilitas dosen dalam hal ini memang berpengaruh terhadap kecurangan akademik mahasiswa. Akan tetapi secara mengejutkan bahwa pengaruhnya positif. Hal ini berarti semakin kredibel dosen maka justru akan membuat mahasiswa semakin terdorong untuk melakukan kecurangan akademik. Pemikiran dosen tentang rencana, tugas, dan penilaian menjadi indikator dengan sumbangsih tertinggi atau terpenting. Jika dijabarkan lebih lanjut maka dosen yang memiliki rencana yang jelas dalam mengajar, memberikan tugas kuliah dengan jelas, memberikan penilaian yang terukur terhadap mahasiswa akan menyebabkan mahasiswa melakukan kecurangan akademik. Secara garis besar berarti dalam persepsi mahasiswa, dosen yang serius dan kredibel atau nampak profesional dalam mengajar akan menyebabkan mahasiswa mengeluh dan tidak percaya diri. Keluhan dan ketidakpercayaan diri mahasiswa ini yang menjadikan mahasiswa semakin melakukan kecurangan akademik.

Semakin Kredibel dosen di prodi Pendidikan Ekonomi Unesa maka literasi ekonomi mahasiswa juga akan naik. Hal ini wajar adanya karena semakin baik dosen dalam mengajar entah itu menggunakan metode, kurikulum mapun media pembelajaran yang baik atau inovatif pasti akan meningkatkan hasil belajar mahasiswa (Rafsanjani et al., 2019). Hasil belajar yang dimaksud dalam penelitian ini adalah literasi ekonomi. Dengan kata lain kredibilitas merupakan agen yang dapat mempengaruhi (de Guzman et al., 2007). Sebagai tambahan kecurangan akademik ternyata tidak memediasi pengaruh kredibilitas dosen terhadap literasi ekonomi mahasiswa.

Walapun banyak mahasiswa yang beranggapan bahwa dengan melakukan tindakan curang maka hasil belajar seperti UTS dan UAS akan meningkat. Tetapi nyatanya hasil penelitian ini menunjukkan bahwa hal ini tidak terbukti. Tinggi maupun rendahnya kecurangan akademik yang dilakukan mahasiswa tidak akan ada artinya terhadap prestasi akademik. Indikator yang memiliki sumbangsih tertinggi di kecurangan akademik mahasiswa adalah menyalin jawaban orang lain tanpa sepengetahuannya. Sebagian besar mahasiswa paling banyak melakukan jenis kecurangan ini walaupun sudah dijaga dan diperingatkan oleh pengawas ujian. Hal ini menjadi masukan bagi prodi Pendidikan ekonomi Unesa untuk bisa mengintervensi mahasiswanya agar mereka tidak melakukan kecurangan akademik (Donse \& Groep, 2013). Hal tersebut akan sia-sia dan tidak akan bisa meningkatkan hasil belajar mereka dalam hal ini adalah literasi ekonomi. Selain itu, jika pengajar adalah dosen yang kredibel sebaiknya mahasiswa mengikuti apa yang dikehendaki dosen dan tidak melakukan kecurangan akademik. Jika hal tersebut dilakukan maka hasil belajar mereka akan meningkat.

\section{SIMPULAN DAN SARAN}

Kredibilitas dosen penting dalam pembelajaran ekonomi akan tetapi kesan dosen serius dan professional justru akan mendorong mahasiswa melakukan kecurangan akademik. Kecurangan akademik mahasiswa ternyata tidak memediasi pengaruh kredibilitas dosen terhadap literasi ekonomi mahasiswa.

Saran yang dapat diberikan pada Prodi Pendidikan ekonomi Unesa adalah memberikan masukan kepada mahasiswa bahwa kecurangan akademik (terbanyak menyalin jawaban teman) tidak akan meningkatkan hasil belajar mereka. Saran untuk peneliti berikutnya adalah mencari variabel lain yang dapat meningkatkan literasi ekonomi mahasiswa baik dari segi internal mahasiswa maupun eksternal. 
Tentunya bisa secara langsung maupun tak langsung (mediasi atau moderasi).

\section{DAFTAR PUSTAKA}

Aningsih, A. V., \& Soejoto, A. (2018). Pengaruh Status Sosial Ekonomi Orang Tua dan Hasil Belajar Mahasiswa Terhadap Tingkat Literasi Ekonomi Mahasiswa. JPEKA: Jurnal Pendidikan Ekonomi, Manajemen Dan Keuangan, 2(1), 11. https://doi.org/10.26740/jpeka.v2n1.p $11-18$

Austin, Z., Collins, D., Remillard, A., Kelcher, S., \& Chui, S. (2006). Influence of Attitudes Toward Curriculum on Dishonest Academic Behavior. American Journal of Pharmaceutical Education, 70(3), 18.

de Guzman, A. B., Ormita, M. J. M., Palad, C. M. C., Panganiban, J. K., Pestaño, H. O., \& Pristin, M. W. P. (2007). Filipino nursing students' views of their clinical instructors' credibility. Nurse Education Today, 27(6), 529533.

https://doi.org/10.1016/J.NEDT.2006. 08.013

Donse, L., \& Groep, I. H. van de. (2013). Academic Dishonesty Among College Students: Predictors and Interventions. Social Cosmos, 4, 4047.

Edwards, A., Edwards, C., Spence, P. R., Harris, C., \& Gambino, A. (2016). Robots in the classroom: Differences in students' perceptions of credibility and learning between "teacher as robot" and "robot as teacher." Computers in Human Behavior, 65, 627-634.

https://doi.org/10.1016/J.CHB.2016.0 6.005

Ghofur, M. A. (2013). Kredibilitas Dan Otentisitas Guru Kewirausahaan Terhadap Karakter Kewirausahaan Siswa Smk Negeri Di Surabaya. Jurnal Ekonomi Pendidikan Dan Kewirausahaan, 1(1), 39. https://doi.org/10.26740/jepk.v1n1.p3 9-52

Hakim, L., Soesatyo, Y., Dwiharja, L. M.,
Prakoso, A. F., Kurniawan, R. Y., Marlena, N., \& Widayati, I. (2018). The Impact of Alienation Through Neutralization on Students' Academic Dishonesty. Journal of Teaching in International Business, 29(2), 161179.

https://doi.org/10.1080/08975930.201 8.1480990

Lambert, E. G., Hogan, N., \& Barton, S. M. (2003). Collegiate academic dishonesty revisited: What have they done, how often have they done it, who does it, and why did they do it? Electronic Journal of Sociology, 7, 127.

Murniatiningsih, E. (2017). Pengaruh Literasi Ekonomi Siswa, Hasil Belajar Ekonomi, Dan Teman Sebaya Terhadap Perilaku Konsumsi Siswa Smp Negeri Di Surabaya Barat. Jurnal Ekonomi Pendidikan Dan Kewirausahaan, 5(1), 127-156. https://doi.org/p-ISSN 2303-324X, eISSN 2579-387X

Rafsanjani, M. A., Sholikhah, N., \& Prakoso, A. F. (2019). Does the "Idaman Jelita" Character of Universitas Negeri Surabaya Influence Students Economics Literacy? Dinamika Pendidikan, 14(2), 205-215. https://doi.org/10.15294/DP.V14I1.22 214

Sagoro, E. M. (2013). Pensinergian Mahasiswa, Dosen, Dan Lembaga Dalam Pencegahan Kecurangan Akademik Mahasiswa Akuntansi. Jurnal Pendidikan Akuntansi Indonesia, 11(2), 54-67. https://doi.org/10.21831/jpai.v11i2.16 91

Sahroh, A. F. (2018). Pengaruh Literasi Ekonomi Dan Tingkat Penggunaan Media Sosial Terhadap Minat Berwirausaha Mahasiswa Fakultas Ekonomi Di Universitas Negeri Surabaya. Jurnal Pendidikan Ekonomi (JUPE), 6(3), 2018-2215.

Solimun, Fernandes, A. A. R., \& Nurjannah. (2017). Metode Statistika Multivariat Pemodelan Persamaan Struktural (SEM) Pendekatan WarpPLS. Malang: Universitas 
Brawijaya Press.

Walstad, W. B., Rebeck, K., \& Butters, R. B. (2013). Test of Economic Literacy. New York: Council for Economic Education.

Zulatsari, M. L. R., \& Soesatyo, Y. (2018). Pengaruh Literasi Ekonomi Dan Pendidikan Kewirausahaan Terhadap Minat Berwirausaha Pada Mahasiswa Jurusan Pendidikan Ekonomi Fakultas Ekonomi Universitas Negeri Surabaya Angkatan 2015. Jurnal Pendidikan Ekonomi, 6(3), 157-160. 